\title{
High temperature interfacial tension measurements of PA6/PP interfaces compatibilized with copolymers using a spinning drop tensiometer
}

(short title: PA6/PP interfacial tension with copolymers)

Claude Verdier ${ }^{a}$, , Harry T. M. Vinagre ${ }^{b}$, Monique Piau ${ }^{a}$ and Daniel D. Joseph ${ }^{b}$

$a_{\text {Laboratoire de Rhéologie }}^{\#}$, BP 53, Domaine Universitaire, 38041 Grenoble Cedex 9, France

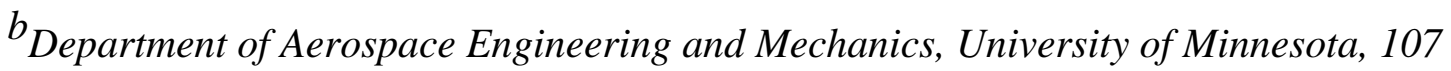
Akerman Hall, 110 Union Street SE, Minneapolis, MN 55455, USA

\begin{abstract}
Interfacial tension measurements of polyamide/polypropylene (PA6/PP) interfaces are reported at high temperature, using a spinning drop tensiometer, especially adapted to the study of the effects of copolymers.

Copolymers in different amounts are included in the PP drop, and their migration towards the interface is inferred from the evolution of the drop diameter during the experiment. The importance of the compatibilizer is studied; small amounts of copolymer give rise to a significant decrease of the interfacial tension. This is due to effective migration of the copolymer, as deduced from diffusion coefficients. Above a critical concentration, the interfacial tension increases again. This phenomenon has not been observed before for such systems and is attributed to the presence of micelles in the bulk which prevent the copolymer migration through the creation of yield stresses.
\end{abstract}

(Key-Words: interfacial tension; copolymer; spinning drop tensiometer; high temperature)

\footnotetext{
* To whom correspondence should be addressed. Fax. (33) 4-76-82-51-64, E-mail: Claude.Verdier@ujf-grenoble.fr

\# Université Grenoble I, Institut National Polytechnique de Grenoble, CNRS (UMR 5520)
} 


\section{INTRODUCTION}

The influence of copolymers at interfaces has been studied intensively during the past decade, they are shown to be very effective in improving the mechanical properties of blends of immiscible polymers [1] as well as the adhesion between two such polymers [2]. A very small amount of copolymer added to the blend can produce drastic changes [1]. However, it is still common in the industry to compatibilize blends with large amounts of copolymers.

When dealing with molten polymers, the addition of copolymers has an effect on the morphology of the blend. Desired mechanical properties [1] (yield stress, elongation at break) may be obtained corresponding to different morphologies. These morphologies are very dependent on the addition of diblock or triblock copolymers. Well-dispersed small phases (domains) are generally desired when manufacturing a polymer blend [3]. The effect of concentration of the copolymer on the morphology has been discussed by many authors. The influence of the type of copolymer seems to be well understood, as well as the rôle of entanglements [4], chain length [5-6], areal density [5], [7-8], and architecture [9-11]. Diblock copolymers seem to be more effective in changing the blend properties, because they locate easily on one or the other side of the interface, whereas a triblock copolymer has to lie across the interface and is therefore less efficient. Molecular theories have been developed [12-14], to take these parameters into account. Furthermore, the addition of surfactant can be done in two ways: it can be mixed with the polymer beforehand or included so that the copolymer is formed by chemical reaction in situ. The last method is therefore more efficient because it permits one to locate the copolymer where needed, especially at the interface [15-16].

In immiscible melts, the interfacial tension is an important parameter which changes non-linearly due to the presence of compatibilizers. Several studies have shown that small quantities of compatibilizer reduce interfacial tension of polymeric systems by sometimes up to $80 \%$ [17-22]. In a strict analogy to water-surfactant systems the critical micelle concentration (cmc) is a relevant parameter [23]; the cmc is a typical 
concentration above which micelles are present in the system. Interfacial tension is sometimes found to decrease linearly or logarithmically until the $\mathrm{cmc}$ is reached, then it levels off; however measured results for higher concentrations at high temperatures are not available.

The measurement of interfacial tension between molten polymers is difficult [18-19,23-28]. The difficulties are associated with high viscosities and small density differences which make it difficult to reach equilibrium, impurities present in the sample and the high temperatures required. Therefore, methods like drop volume, pendant drop and breaking threads, which rely on small driving forces which cannot be controlled, like gravity or capillarity, are less reliable than the spinning drop for which centripetal gravity is controlled and can be driven to high levels.

In this paper, the influence of the addition of a copolymer on the interfacial tension between two molten polymers is investigated. Polypropylene-polyamide (PP/PA6) systems are used, and the copolymer contains polypropylene (PP) and polyacrylamide (PA6), the major part being PA6. The materials are described in the first part.

A spinning drop tensiometer [29-30] (US. Patent \# 4,644,782, Www.SDTensiometer.com) and its recent improvements [31] are used to determine the interfacial tension between these polymer melts. The apparatus is briefly described in section two, as well as an original device for melting polymers in order to manufacture the samples to be used in the tensiometer.

The next section is devoted to the study of the effects of adding copolymer to a drop (PP) in a PA6 matrix. The influence of including copolymer to both the drop (PP) and matrix (PA6) is also investigated. The main variable for these studies is the volume concentration of the copolymer.

In the last section of this paper, the influence of the speed of diffusion of the copolymer towards the interface is estimated using droplet diameter versus time 
diagrams with the aim of determining the effect of interface covering by copolymers, as well as the efficiency of the copolymer.

\section{EXPERIMENTAL SECTION}

\section{Materials: PP, PA6 and copolymer}

The polymers used are commercial ones, and their properties are listed in table 1. The compatibilizer used in this study is a copolymer which contains parts of polyamide and parts of polypropylene. The major component is polyamide.

The morphology of similar PP/PA6 systems including a copolymer has been investigated previously using ultrasound [32] In this case, PPmal-g-PA11 was used, and good emulsification was obtained. Such copolymers seem to be good candidates for reducing domain sizes (micron size). The morphology of PA6-PP blends modified with maleated rubbers can also be changed drastically [33-34]. The effect of bonding temperature and time during in situ formation of block copolymers in such systems is also important [16], for it allows the mobility of the copolymer. The viscosity ratio between polypropylene and nylon 6 has been shown not to be significant for predicting phase inversion in such blends, but it leads to different particle sizes [35]. Finally, the effect of the mixing procedures [36] shows that improved phase morphology is obtained when using single-step blending. Therefore, such systems are expected to show a significant interfacial tension change, when adding such copolymers.

The copolymer has been mixed with PP or PA6 during separate extrusion processes in a twin-screw extruder. The volume concentration of copolymer in each sample varies up to $30 \%(1 \%-5 \%-10 \%-20 \%-30 \%)$. The PA6 and copolymer-PA6 systems are still transparent at the operating temperatures, and will allow visualization of the drop, as explained in the next section. Moreover no data on higher copolymer concentrations is yet available in the literature.

Density measurements are given in table 2 . The density was determined using a capillary rheometer (Göttfert 2001). By imposing a constant velocity for the piston, the 
flow rate $\mathrm{Q}\left(\mathrm{m}^{3} / \mathrm{s}\right)$ can be found. Then the mass rate $\mathrm{M}(\mathrm{kg} / \mathrm{s})$ is obtained from an automated precision balance, therefore the ratio M/Q gives the density for the different polymers and blends.

There is considerable data for usual polymeric systems [37-44], but few for the PP-PA6 systems. The same order of magnitude for interfacial tension $\left(10-15 \mathrm{~mJ} / \mathrm{m}^{2}\right)$ has been found for PP-PA6 [24] and EP-PA6 systems (ethylene-propylene copolymer and polyamide-6) [25] .

\section{The spinning drop tensiometer}

The spinning drop tensiometer is widely used for measuring interfacial tension and considered to be one of the best methods for measuring small values of tension [3738]. Further details may be found in previous works by the authors [29-31]. If the speed range of the motor is wide and the testing tube permits the formation of a large bubble, the spinning drop tensiometer can be used to make accurate measurements of both small and large tensions. Unlike other methods, it can be used to measure tension in fluids with high viscosity and/or small density difference; with an adequate oven measurements can be taken in a wide range of temperatures. The spinning drop tensiometer which was developed (see figure 1) has all these desirable features, is one of the most versatile instruments presently available to measure interfacial tension and is particularly adapted to measurements required for melted polymers.

Most of the so-called shape methods rely on gravity to deform a drop in order to measure interfacial tension; long times are required for reaching equilibrium due to high viscosities but these polymeric systems undergo risks of polymer degradation. The spinning drop tensiometer uses centripetal acceleration to control shape; the time to equilibrium can be controlled by over and under spinning [45].

A spinning polymer drop (small density) is rotated inside another immiscible polymer (high density). The balance of inertial and interfacial forces leads to Vonnegut's formula [37] for the interfacial tension $\gamma\left(\mathrm{J} / \mathrm{m}^{2}\right)$ 


$$
\gamma=\frac{\left(\rho_{2}-\rho_{1}\right) \omega^{2} d^{3}}{32}
$$

where $\rho_{1}\left(\mathrm{~kg} / \mathrm{m}^{3}\right)$ is the density of the drop, $\rho_{2}\left(\mathrm{~kg} / \mathrm{m}^{3}\right)$ is the density of the heavier fluid, $\omega(\mathrm{rad} / \mathrm{s})$ is the angular velocity of rotation and $\mathrm{d}(\mathrm{m})$ is the diameter of the drop. Equation (1) is valid under the assumption that the drop is in equilibrium and its length is larger than four times its diameter.

Images of the drop are captured from the camera with a frame grabber in a Pentium II computer. Pictures may be collected every second and played in real time, stored in the computer for later processing using dedicated NT Microsoft ${ }^{\mathrm{TM}}$ software. The software measuring system is calibrated using a post with known diameters embedded in the heavier fluid. This allows the measuring of the drop diameter without corrections of index of refraction.

In the design of the tensiometer, special care has been taken to insure good temperature control, absence of vibrations at high velocities, and data acquisition done on the computer [31]. Also, measurements of diameter versus time allow the determination of relaxational and extensional properties of polymeric systems [30] as well as characteristic times (migration of a compatibilizer is an example).

\section{Manufacturing solid samples}

Most polymers are solid at room temperature and are available commercially in the form of beads, flakes, powders or chunks. Starting with these raw materials, samples to be used in the tensiometer have been prepared by melting and forming the polymers in an oven. This special oven was built for this purpose and a method was developed to form different samples. This method is very reliable, inexpensive and produces samples under vacuum, free of contamination and no oxidation. With this method rods of very brittle polymers (polystyrene) with a molecular weight of 50,000 $\mathrm{g} /$ mole can be formed. 
The forming-oven is shown in figure 2. It consists of an aluminum cylinder with a central chamber. The cylinder contains heating elements $(2 \mathrm{~kW})$. The polymer is molten in a glass tube (12 $\mathrm{mm}$ diameter), which is centered inside the cylinder and positioned vertically using two guides. The top-plug has a small hole $(0.5 \mathrm{~mm}$ in diameter) through its center that can be connected to a vacuum pump. The lower guide is spring loaded to accommodate for different glass tube lengths. It also has a through hole where a rod pushes the sliding-plug with post from the bottom, when the polymer is molten. The sliding-plug at the bottom seals the glass tube.

A sample consists of three parts (figure 3). Part A (denser polymer) is the lower one, which has the calibration post. Part B (denser polymer) is the upper part; it contains the drop of lighter polymer (Part C). The copolymer can be included in the drop (C) or in both other parts (A and B). Usually it will be included in the drop.

The polymer beads (flakes or powder, about 8 grams) are loaded into the glass tube (figure 2) and the other end is sealed with the top-plug. First a vacuum is achieved. Heating the system takes about 15 minutes and cooling about one hour. In general, the target temperature should be a value 10 to $20^{\circ} \mathrm{C}$ above the melting temperature of the polymer. When melting the polymer, the spring loaded pushing rod (bottom) moves up so that the polymer is compressed. When cooling, the pushing rod also moves down to compensate for volume change.

Figure 2 shows a situation where a sliding-plug with post has been used at the bottom, therefore part B is obtained after melting the beads. For making part A, the same procedure is used, except that the sliding-plug with post is replaced in figure 2 by a sliding-plug with the calibration post. Finally, the last part $\mathrm{C}$ is made using a special Teflon ${ }^{\mathrm{TM}}$ cylindrical die to form a rod of lighter polymer.

The whole process takes about two hours and a half, producing a good sample in about $80 \%$ of the trials. After putting the different pieces together in the glass tube (Figure 3) which is then set on the tensiometer, vacuum is achieved and the experiment can start. 


\section{INFLUENCE OF THE LOCATION OF THE COMPATIBILIZER}

In studying the effects of copolymers it has first to be decided whether the copolymer should be inside or outside the drop, or both.

The first set of experiments were carried out with the copolymer inside the PP drop (1\%). The interfacial tension was found to be $13.4 \mathrm{~mJ} / \mathrm{m}^{2} \pm 1 \mathrm{~mJ} / \mathrm{m}^{2}$ (see label 1 on figure 4 or table 3 ), a clear reduction compared to the value of $15.8 \mathrm{~mJ} / \mathrm{m}^{2}$ obtained without any compatibilizer.

In a new set of experiments, the copolymer was located both in the PP drop (1\%) and in the PA6 matrix (1\%). These experiments show that interfacial tension equals roughly $9.0 \mathrm{~mJ} / \mathrm{m}^{2} \pm 1 \mathrm{~mJ} / \mathrm{m}^{2}$ and is reduced even more, as expected because there is more copolymer present at the interface. These experimental points are also shown in figure 4 (label 1+). This labeling is used because the copolymer concentration in the PP drop is still 1\%. Nevertheless, there is actually more copolymer because of the extra polymer chains situated in the outer fluid.

This result is important and shows that covering of the interface is not achieved completely with $1 \%$ copolymer included inside PP, but optimal reduction may be expected when going to higher concentrations. Such reduction of the interfacial tension is a usual result at low concentrations, when an adequate compatibilizer is used. It is explained by the fact that the A-B copolymer locates on each side of the interface between $\mathrm{A}$ and $\mathrm{B}$, therefore giving rise to a more stable interface (thermodynamically speaking) and a smaller interfacial tension.

In the next part, the copolymer will be located inside the PP drop only, in order to study the effect of copolymer concentration.

\section{INTERFACIAL TENSION VS. COPOLYMER CONCENTRATION}

Interfacial tension data as a function of copolymer concentration is collected in table 3 at a temperature of $260^{\circ} \mathrm{C}$. At low concentrations (below 5\%), the experiments were carried out twice, as indicated in the same table. The concentration of the 
copolymer is expressed as a fraction of the total volume of the PP drop. The graph of interfacial tension vs. concentration is depicted in figure 4.

A rapid decrease of the tension with copolymer concentration is observed first. This result was expected from the literature [24] and validates our method further. The copolymer covers part of the interface when its concentration is small. It should cover the whole interface for a certain concentration, presumably the critical micelle concentration $(\mathrm{cmc})$, and the interfacial tension should reach a minimum.

The next part of the curve (concentration of 5\% and above) shows a surprising rise of the tension as the concentration increases. This increase is not predicted by any theories known to us. In many surfactant systems which are better understood, the surface tension levels off after the cmc. However, aqueous surfactant systems giving rise to a fall in tension with concentrations below the cmc followed by an increase for concentrations larger than the cmc have been reported [15]. In the present case, the interfacial tension starts at a value of around $15.8 \mathrm{~mJ} / \mathrm{m}^{2}$, decreases to at least $8 \mathrm{~mJ} / \mathrm{m}^{2}$, then increases again to about $14-15 \mathrm{~mJ} / \mathrm{m}^{2}$ for the $20 \%$ case. Values of the same order have been obtained by Jannerfeldt et al. [24] at a different temperature $\left(225^{\circ} \mathrm{C}\right)$. It is conceivable that micelles give rise to a yield stress at the higher concentrations (> 5\%) or because of other reasons which we do not understand. This will be discussed in the next section. The last data point $(30 \%)$ drawn on the graph may be too high; the system may not have reached equilibrium.

It is probable that as in the case of aqueous surfactants the copolymers preferentially occupy the interface: after the interface is saturated the copolymers associate with each other in micellar aggregates. Though the data here is not sufficient to establish which of several theories gives a valid description of the action of copolymers, we may conclude that in the system studied here, the optimal concentration for tension reduction lies between $1 \%$ and $5 \%$. Of course, when using industrial systems where a large number of drops coexist, it may be better to use higher amounts of copolymer to cover larger surfaces. 


\section{DIFFUSION OF THE COPOLYMER. MIGRATION TIMES}

Diffusion of the copolymer towards the interface is very important in terms of efficiency of one copolymer or another. The more efficient the copolymer, the faster it diffuses to the interface. Depending on the location of the copolymer, different results may be obtained. As seen recently [46], the way a compatibilizer goes to the interface is crucial: using a conical die in coextrusion for instance helps to place the compatibilizer closer to the interface; reaching equilibrium in interfacial tension measurements with such systems is faster. In the present experiment, it is the centripetal acceleration which brings the copolymer to the interface, because its density lies in between densities of the two other polymers, but diffusion also needs to be considered. There is effective migration of the copolymer because a decrease of the interfacial tension by about $50 \%$ is observed, at least for the low concentrations.

To investigate these effects better, diagrams giving drop diameter $\mathrm{d}(\mathrm{t})$ versus time $t$ may be reported [29-30]. One can reduce the diameter data with the final diameter $\mathrm{d}$ and plot $\mathrm{d} / \mathrm{d}-1$. An adequate dimensionless parameter, as shown in Ref. [31] is $t \gamma /\left(\mu_{1}+\mu_{2}\right) \mathrm{d} \quad\left(\mu_{1}\right.$ and $\mu_{2}$ are the viscosities of PP and PA6 respectively). This representation has the advantage to show how fast the diameter reaches its final size $\mathrm{d}$. In the initial stages where diffusion prevails, the change in $\mathrm{d}(\mathrm{t})$ will tell how fast the copolymer diffuses to the interface.

The variations of $d / d-1$ vs. $t \gamma /\left(\mu_{1}+\mu_{2}\right) d$ for four previous experiments are depicted in figure 5. The significant decrease to zero ensures that equilibrium is obtained. Variations with $1 \%$ interfacial agent or $1+\%$ (see definition above) are slower and similar to each other and the reaching of equilibrium is probably mainly concerned with the migration of the copolymer on each side of the interface. Migration of the copolymer is slow, therefore longer migration times may be needed to reach equilibrium. Note that there is no migration when there is no copolymer.

Gaines et al. [47] proposed a diffusion law to account for the migration of the additive to the interface. This model is derived from Fick's law with a diffusion 
coefficient D independent of concentration; it assumes that the molecules arriving at the interface are adsorbed rapidly. The interfacial tension $\gamma$ is shown to decrease as:

$$
\gamma=\gamma_{0}-2 \operatorname{RTc}_{0}\left(\frac{\mathrm{Dt}}{\pi}\right)^{1 / 2}
$$

where $\gamma_{0}$ is the interfacial tension at time $0, \mathrm{c}_{0}$ is the bulk concentration of the additive, $\mathrm{R}$ is the gas constant, $\mathrm{T}$ is temperature and $\mathrm{D}$ is the diffusion coefficient. By looking at the curve corresponding to $\varepsilon=0$ in figure 5 , it can be deduced that reaching equilibrium corresponds to a transient motion with a typical decrease of the diameter at higher reduced times. This variation has been observed previously [30] and is attributed to combined relaxational properties of both polymers. The curves obtained for $\varepsilon=1$ and $1+$ are different because the copolymer starts to migrate to the interface, then relaxation occurs, as seen by the similar curves at longer times. At small times, following Ref. [47], one may try to determine the diffusion coefficient by using Eq. (2). This is represented by the curve fits in figure 6 .

The theory fits the data reasonably well, and may be used to provide a diffusion coefficient of the copolymer in these two cases $(1$ and $1+)$, since this is where effective diffusion happens. Two diffusion coefficients $\mathrm{D}_{1}=2.8510^{-8} \mathrm{~cm}^{2} \mathrm{~s}^{-1}$ and $\mathrm{D}_{1+}=4.38$ $10^{-8} \mathrm{~cm}^{2} \mathrm{~s}^{-1}$ are obtained; these values are of the order of magnitude expected for such systems (see for example Refs.[47-48]), where the copolymer is found to be efficient. The higher coefficient $\mathrm{D}$ in the second case may be associated to faster diffusion, as expected because of the greater amount of polymer involved, which moves to the interface from both sides. The method used here is therefore interesting for comparing the efficiency of copolymers in terms of their coefficients of diffusion.

On the other hand, it seems from figure 5 that the reaching of equilibrium is faster for the 5\% case. Actually, the system seems to stop rapidly at its final position (d ). An explanation of this can be based on physico-chemical principles. Polypropylene (PP), which involves mainly dispersive interactions does not have affinities with the Polyamide (PA6), which likes water and develops polar interactions. 
Copolymers located in the drop bulk migrate rapidly towards the interface in the low concentration cases (1 and 1+), because they do not like being associated with PP. As soon as the concentration has reached the critical micellar concentration $(\mathrm{cmc})$, the interface is completely saturated with copolymers, and there is no more space for them to go: therefore they will stay inside the drop and form micelles. This tends to create shear yield stresses, which eventually stop the migration, therefore, reaching $d$ is rather fast. This may explain that the values obtained for the interfacial tension is changed because of such effects. The order of magnitude of such shear yield stresses has not been measured to our knowledge but could be in the range of a few thousands $\mathrm{Pa}$ (similarly to gels [49]), due to the weak interactions between micelles. Inside the drop, shear stresses are presumably smaller than this value, therefore they are not high enough to create any further motions of the copolymer chains.

\section{CONCLUSION}

The evolution of interfacial tension as a function of compatibilizer concentration has been studied for PP/PA6 systems using a spinning drop tensiometer. The system also allows one to determine interfacial tension from measurement of the drop diameter. The time needed to obtain an equilibrium diameter is related to the migration time of the copolymer to the interface.

Copolymers have been included in the drop of lighter polymer (PP). It is shown that, as in other systems, the presence of a copolymer reduces first the interfacial tension, and this can occur at very low concentrations. In such cases, estimates of diffusion coefficients have been made. Above a certain concentration, the presence of micelles prevents diffusion of the copolymer.

The method of studying compatibilizers used in this paper seems very promising for predicting the influence of the effects of molecular weight, architecture and randomness of copolymers. 


\section{ACKNOWLEDGMENTS}

The authors wish to thank Prof. Alessandro Gandini for his help in characterizing the copolymer and P.-Y. Longin for determining the densities of the various fluids. 


\section{REFERENCES}

1. Fayt R, Jérôme R, Teyssié Ph. J. Polym. Sci.: Polym. Phys. Ed. 1989;27:775-793.

2. Creton C, Kramer EJ, Hadziioannou G. Macromolecules 1991;24 (8):1846-1853.

3. Macosko CW, Guégan P, Khandpur AK, Nakayama A, Marechal P, Inoue T. Macromolecules 1996;29 (17):5590-5598.

4. Brown HR, Russell TP. Macromolecules 1996;29 (2):798-800.

5. Creton C, Kramer EJ, Hui C-Y, Brown HR. Macromolecules 1992;25 (12):30753088.

6. Dai C-A, Dair BJ, Dai KH, Ober CK, Kramer EJ, Hui C-Y, Jelinski LW. Phys. Rev. Letters 1994;73 (18):2472-2475.

7. Creton C, Brown HR, Deline VR. Macromolecules 1994;27 (7), 1774-1780.

8. Boucher E, Folkers J-P, Hervet H, Léger L, Creton C. Macromolecules 1996;29 (2):774-782.

9. Lyatskaya Y, Gersappe D, Balazs AC. Macromolecules 1995;28 (18):6278-6283.

10. Lyatskaya Y, Gersappe D, Gross NA, Balazs AC. J. Phys. Chem. 1996;100 (5):1449-1458.

11. Lomellini P, Matos M, Favis BD. Polymer 1996;37 (25):5689-5694.

12. Dan N, Tirrell M. Macromolecules 1993;26 (4):637-642.

13. Semenov AN. Macromolecules 1992;25 (19):4967-4977.

14. Wittmer J, Joanny J-F. Macromolecules 1993;26 (11):2691-2697.

15. Mollet C, Touhami Y, Hornof V. J. Colloid Interface Sci. 1996;178:523-530.

16. Bidaux J-E, Smith GD, Bernet N, Manson J-AE, Hilborn J. Polymer 1996;37 (7):1129-1136.

17. Patterson HT, Hu KH, Grindstaff TH. J. Polym. Sci.: Part C 1971;34:31-43.

18. Lucas EF, Oliveira CM, Gomes AS. J. Appl. Polym. Sci. 1992;46:733-737.

19. Elemans PHM, Janssen JMH, Meijer HEH. J. Rheol. 1990;34 (8):1311-1325.

20. Wagner M, Wolf BA. Polymer 1993;34 (7):1460-1464.

21. Chen CC, White JL. Polym. Engng Sci. 1993;33 (14):923-930.

22. Cho K, Jeon HK, Park CE, Kim J, Kim KU. Polymer 1996;37 (7):1117-1122.

23. $\mathrm{Hu}$ W, Koberstein JT, Lingelser JP, Gallot Y. Macromolecules 1995;28 (15):5209-5214.

24. Jannerfeldt G, Boogh L, Manson JAE, J. Polym. Sci.: Part B: Polymer Physics 1999;37:2069-2077.

25. Luciani A, Champagne MF, Utracki LA. Polym. Networks Blends 1996;6 (1):5162.

26. Nose T. Macromol. Symp. 1996;106:261-274. 
27. Nose T, Tanabe T. Macromolecules 1997;30 (18):5457-5463.

28. Rundqvist T, Cohen A, Klason C. Rheol. Acta. 1996;35 (5):458-469.

29. Verdier C, Topics in the fluid mechanics of viscoelastic liquids, Thesis, University of Minnesota, Minneapolis, USA, 1990.

30. Joseph DD, Arney MS, Gillberg G, Hultman D, Verdier C, Vinagre HTM. J. Rheol. 1992;36 (4):621-662.

31. Vinagre HTM, Interfacial tension for polymeric systems and oil emulsions, Thesis, University of Minnesota, Minneapolis, USA,1998.

32. Verdier C, Piau M. J. Phys. D: Appl. Phys. 1996;29 (6):1454-1461.

33. Gonzalez-Montiel A, Keskkula H, Paul DR. Polymer 1995;36 (24):4587-4603.

34. Gonzalez-Montiel A, Keskkula H, Paul DR. Polymer 1995;36 (24):4605-4620.

35. Hietaoja PH, Holsti-Miettinen RM, Seppala JV, Ikkala OT. J. Applied Polym. Sci. 1994;54:1613-1623.

36. Lee J-D, Yang S-M. Polym. Eng. Sci. 1995;35 (23):1821-1833.

37. Vonnegut B. Rev. Sci. Instrum. 1942;13:6-9.

38. Princen HM, Zia IYZ, Mason SG. J. Colloid Interface Sci. 1967;23:99-107.

39. Chappelear DC. Polym. Reprints 1964;5:363.

40. Wu S. J. Phys. Chem. 1970;74:632-638.

41. Wu S. J. Polym. Sci: Part C 1971;34:19-30.

42. Elmendorp JJ, De Vos G. Polym. Engn. Sci. 1986;26 (6):415-417.

43. Anastasiadis SH, Gancarz I, Koberstein JT. Macromolecules 1988;21 (10):29802987.

44. Carriere CJ, Cohen A, Arends CB. J. Rheol. 1989;33 (5):681-689.

45. Joseph DD, Arney MS, Ma G. J. Colloid Interface Sci. 1992;148:291-295.

46. Chapleau N, Favis BD, Carreau PJ. J. Polym. Sci.: Part B: Polymer Physics 1998;36:1947-1958.

47. Gaines GL, Bender GW, Macromolecules 1972;5:82-86

48. Tsunashima Y, Macromolecules 1990;23(11),2963-2969

49. Magnin A, Piau J.-M., J. Non Newt. Fluid Mech. 1989;36, 85-108 


\section{FIGURE CAPTIONS}

Figure 1 General view of the tensiometer.

Figure 2 Oven to form polymer rods. A glass tube with sliding plug and post has been included. In this case, part B is made after melting and cooling.

Figure 3 Solid sample assembled in the glass tube and ready for loading in the tensiometer. Part A: dense polymer with calibration post. Part B: dense polymer with hole for the drop. Part C: drop of light polymer

Figure 4 Interfacial tension vs. concentration of copolymer in PP drop. Label 1 corresponds to a $1 \%$ concentration in the drop, Label $1+$ corresponds to $1 \%$ both in the drop and the outer polymer. The dotted line is a guide for the eye.

Figure 5 Typical reduced diameter vs. reduced time diagram at different compatibilizer concentrations

Figure 6 Reduced diameter vs. reduced time. Comparison between theory [47] and experiment. Best fits obtained for $\mathrm{D}_{1}=2.8510^{-8} \mathrm{~cm}^{2} \mathrm{~s}^{-1}$ and $\mathrm{D}_{1+}=$ $4.3810^{-8} \mathrm{~cm}^{2} \mathrm{~s}^{-1}$ (equation (2)) 


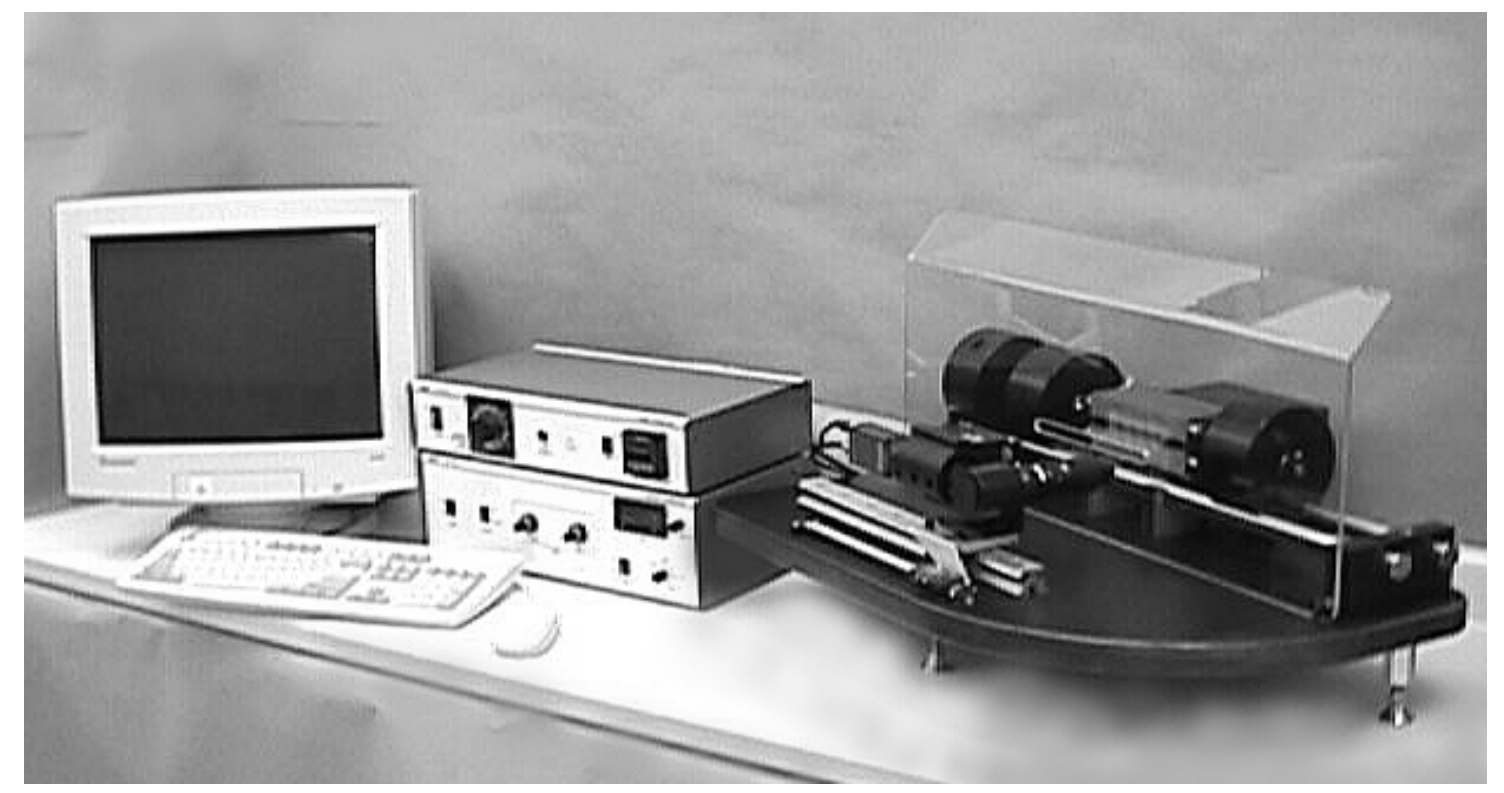

FIGURE 1 


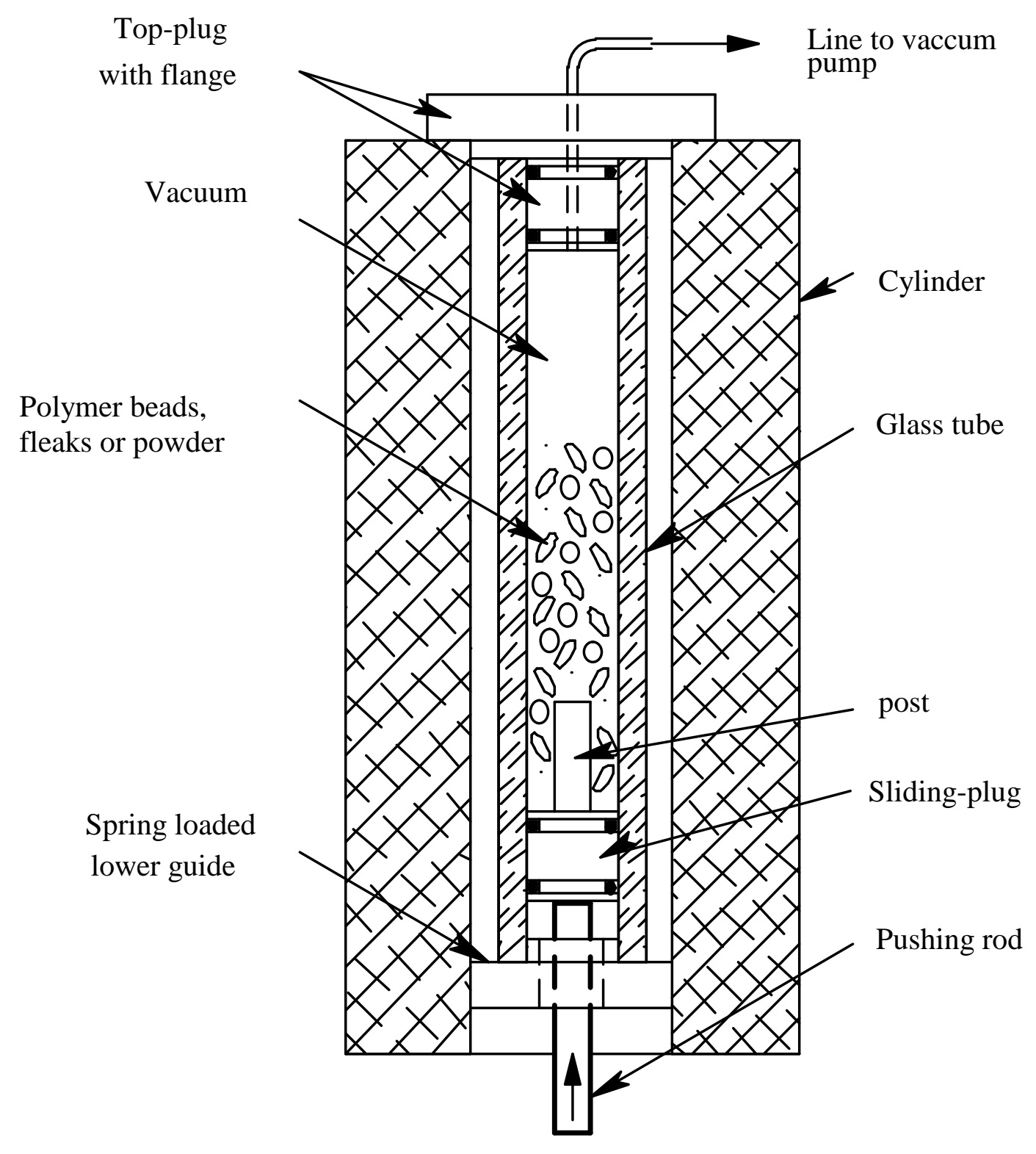

FIGURE 2 


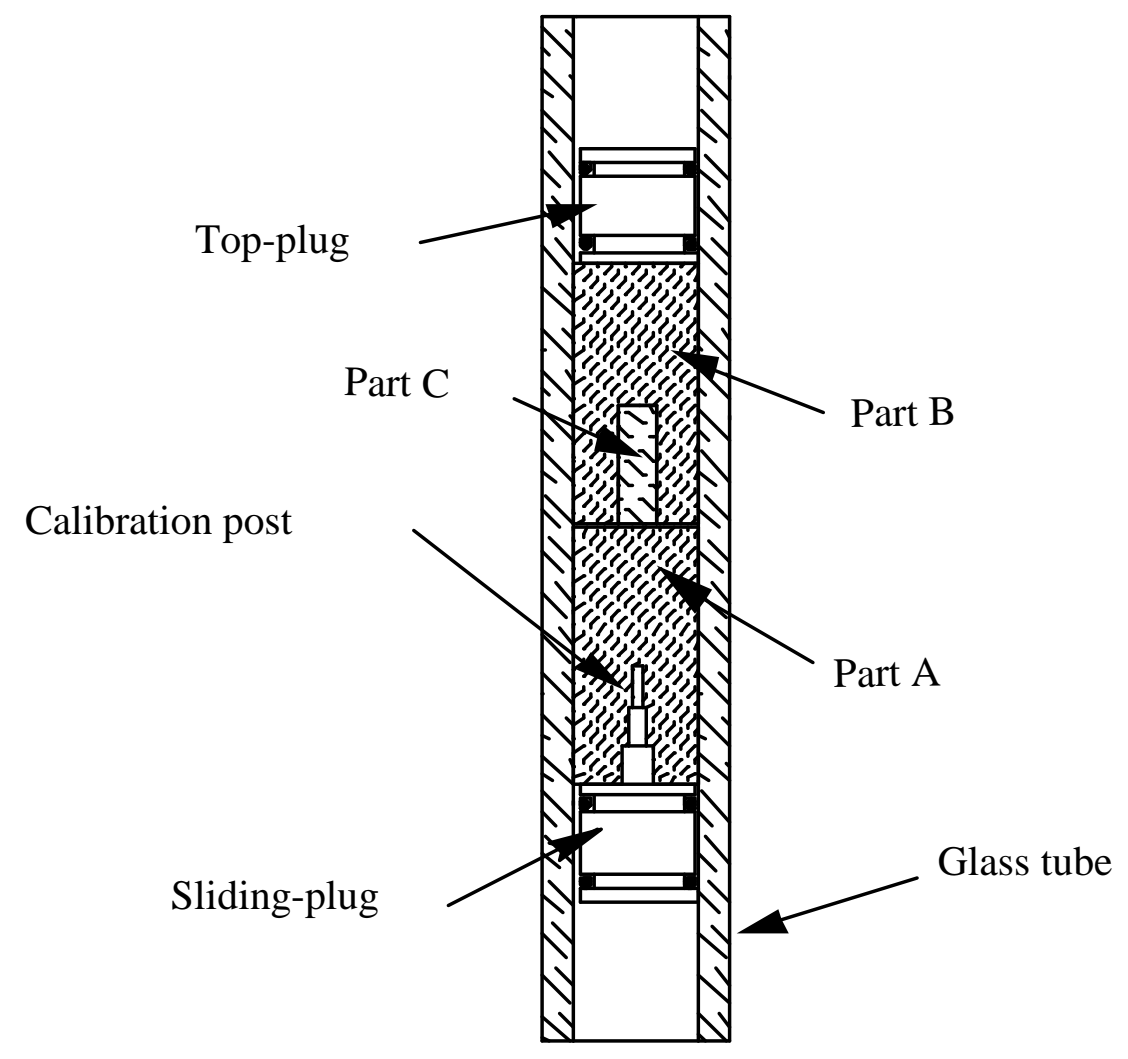

FIGURE 3 


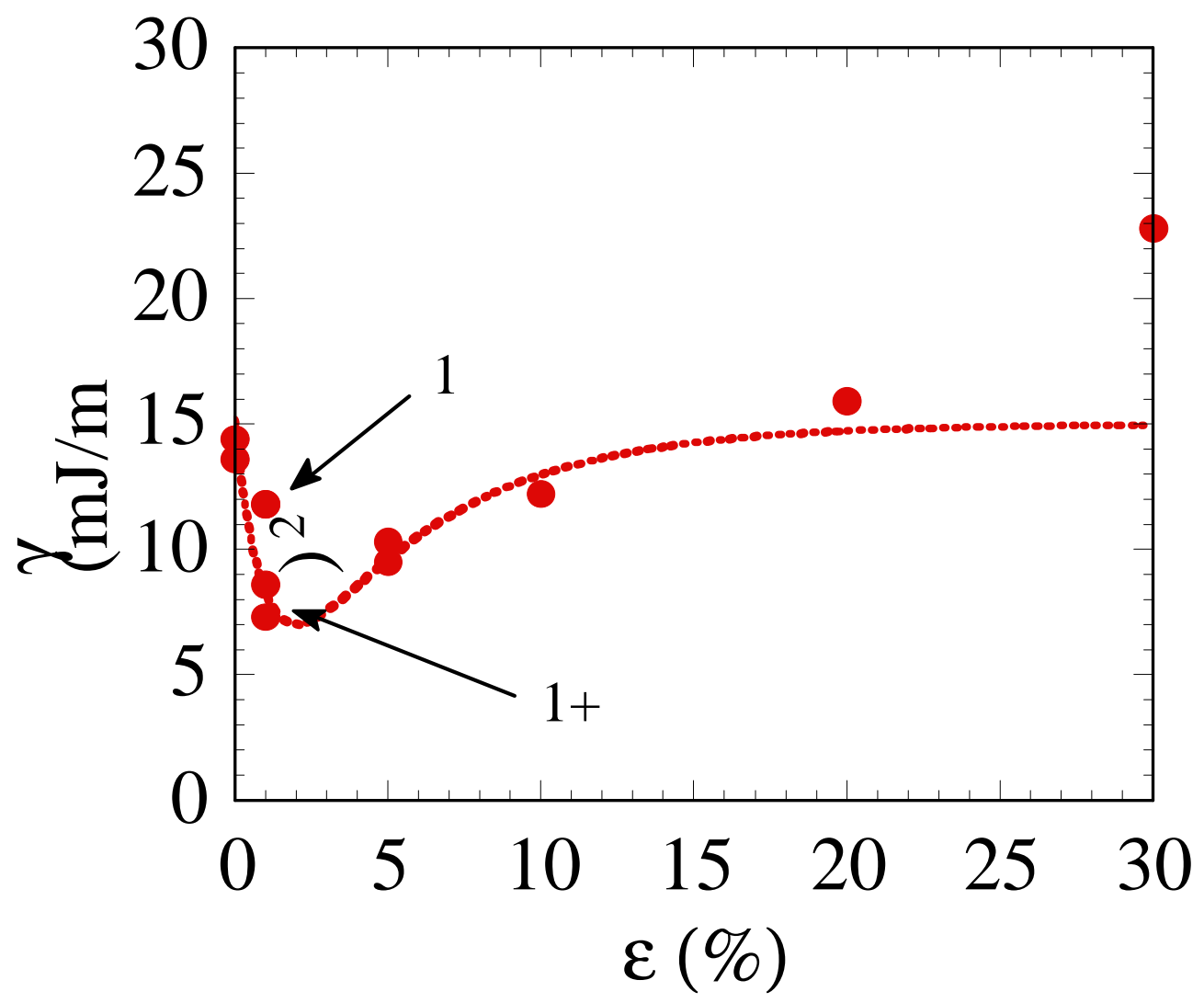

FIGURE 4 


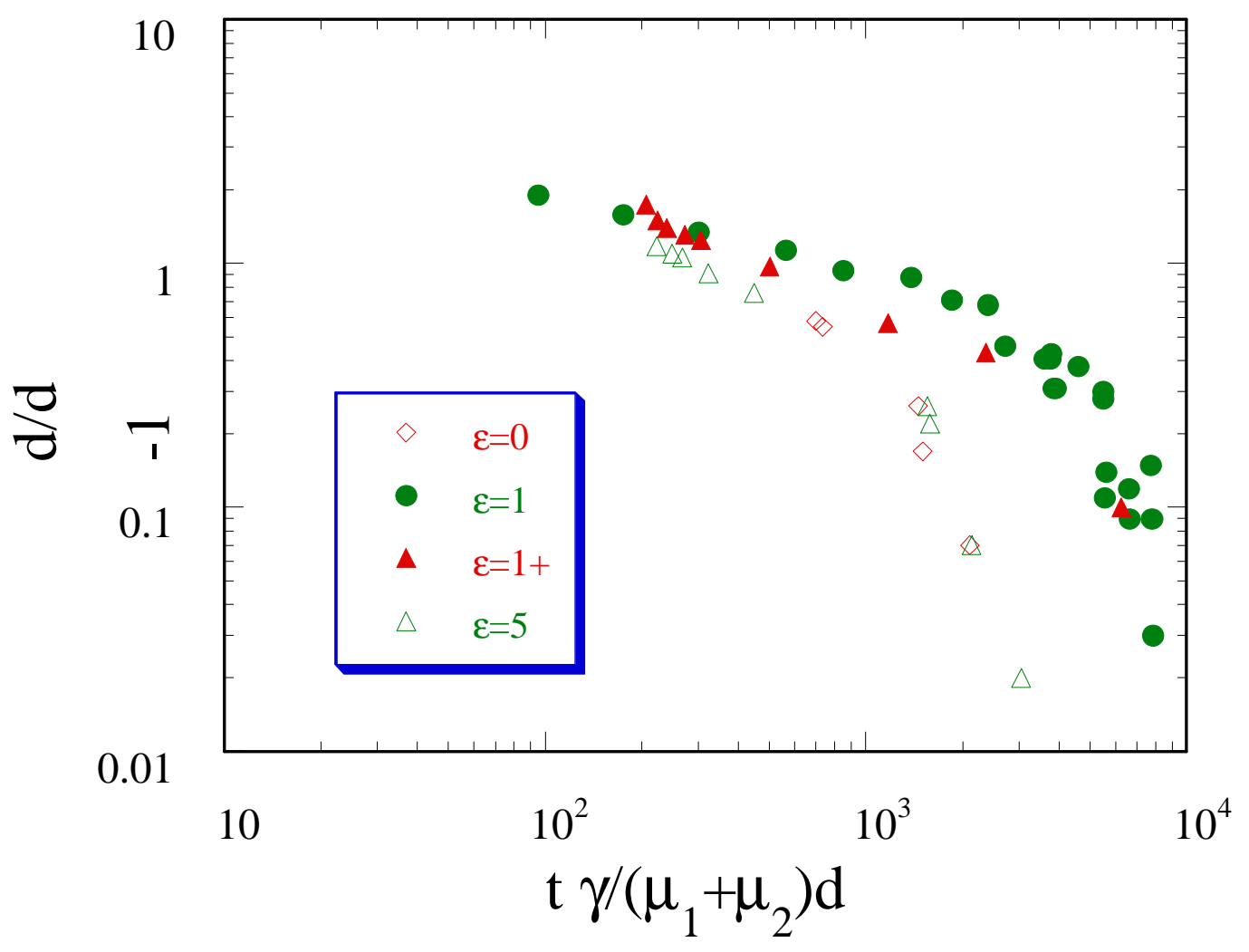

FIGURE 5 


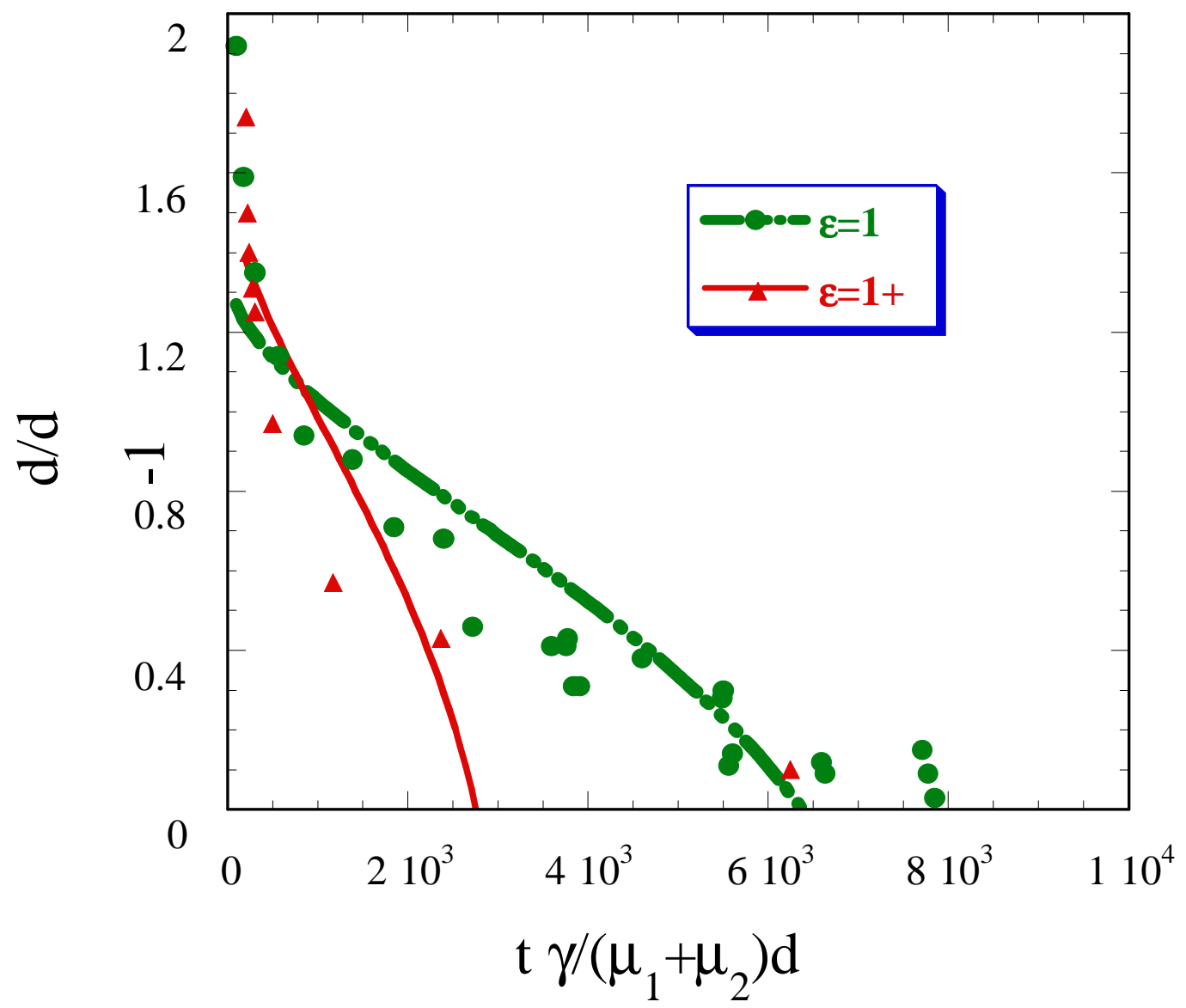

FIGURE 6 


\section{TABLE CAPTIONS}

Table 1 Polymer properties.

Table 2 Densities of polymers at different concentrations of copolymer at $260{ }^{\circ} \mathrm{C}$.

Table 3 Data corresponding to interfacial tension vs. copolymer concentration (fig. 4) 
Table 1

\begin{tabular}{ccc}
\hline Polymer & Type & $\begin{array}{c}\text { Viscosity } \mu \text { at } 260^{\circ} \mathrm{C} \\
(\text { Pa.s })\end{array}$ \\
\hline PA6 & Ultramid B3 & 673 \\
\hline PP & Finasphere 1030S & 1703 \\
\hline copolymer & - & - \\
\hline
\end{tabular}


Table 2

\begin{tabular}{ccccccc}
\hline Concentration (\% vol) & 0 & 1 & 5 & 10 & 20 & 30 \\
\hline$\rho_{1}\left(\mathrm{~kg} / \mathrm{m}^{3}\right)$ & 730 & 731 & 730 & 733 & 743 & 749 \\
\hline$\rho_{2}\left(\mathrm{~kg} / \mathrm{m}^{3}\right)$ & 980 & $980^{*}$ & 980 & 980 & 980 & 980 \\
\hline
\end{tabular}

( ${ }^{*}$ except for experiment where copolymer is also outside: $\rho_{2}=975 \mathrm{~kg} / \mathrm{m}^{3}$ ) 
Table 3

\begin{tabular}{ccccc}
\hline $\begin{array}{c}\text { Volume } \\
\begin{array}{c}\text { concentration } \\
(\%)\end{array}\end{array}$ & $\begin{array}{c}\mathrm{T} \\
\left({ }^{\circ} \mathrm{C}\right)\end{array}$ & $\begin{array}{c}\text { Final diameter } \\
\mathrm{d}(\mathrm{mm})\end{array}$ & $\begin{array}{c}\omega \\
(\mathrm{rpm})\end{array}$ & $\begin{array}{c}\gamma \\
\left(\mathrm{mJ} / \mathrm{m}^{2}\right)\end{array}$ \\
\hline 0 & 260 & 2.236 & 4004 & 15.4 \\
0 & 260 & 1.733 & 6040 & 16.3 \\
\hline 1 & 260 & 2.139 & 4007 & 13.4 \\
1 & 260 & 1.804 & 5168 & 13.4 \\
\hline $1+$ & 260 & 2.208 & 3009 & 8.1 \\
$1+$ & 260 & 1.864 & 4220 & 9.6 \\
\hline 5 & 260 & 2.001 & 4006 & 11.0 \\
5 & 260 & 1.744 & 5117 & 11.9 \\
\hline 10 & 260 & 2.126 & 4208 & 14.4 \\
\hline 20 & 260 & 2.330 & 4298 & 19.0 \\
\hline 30 & 260 & 2.268 & 5508 & 28.0 \\
\hline
\end{tabular}

